\title{
The Analysis of Purdue Online Writing Labs as Second Language Writing Support Tools
}

\author{
Cintya El Meysarah \\ State University of Malang, Indonesia \\ e-mail: elmeysa@gmail.com \\ Sponsored by Indonesia Endowment Fund for Education (LPDP)
}

\begin{abstract}
This study is a review of study, "the uses of and attitudes towards OWLs as second language writing support tools", by Joshua M. Paiz in 2014. In this research review, the researcher tries to give critical views especially on methodology, the way and the instruments that the researcher used and maybe forgot. The purpose of the review, using contrastive analysis, is for consideration in conducting a further better research. By online interviews and survey, the findings come up with five dimensions. Thereto, this review provides some parts specifically on steps, based on Center for Teaching Quality, in developing Purdue OWL to support L2 learning. The review agrees that using Purdue OWL for make learners easier to write is one of the valuable ways to enhance their motivation and ability especially for a second language. Unfortunately, there is still no evidence of previous research about the use of it in rural area; it makes us difficult to generalize the result of benefits in using Online Writing Labs (OWL) to other populations of practitioners.

Keywords: Online Writing Labs, second language, writing tools
\end{abstract}




\section{INTRODUCTION}

OWL exceeds commonplace in just less than two decades. It stands for Online Writing Labs, and the creator of this tool is Purdue University. That is the reason why the name of it, is Purdue OWLs. According to Purdue University (1995-2017), OWL resources provide the learners with the complete writing process: pre-writing (invention), developing research questions and outlines, composing thesis statements, and also proofreading. While the writing process perhaps different for each person and for each particular assignment, the resources contained in that section follow the general work flow of pre-writing, organizing, and also revising. For resources and examaples on specific types of writing assignments, the website provides Common Writing Assignment area. As a reminder, the long objective of the emergence of this Online Writing Labs is to promote autonomous learning especially in writing. A significant proportion of classroom writing may be devoted to self-writing (Brown, 2015). By using exposure of self-writing hopefully the learners will be more autonomous and not always depend on the teacher in the classroom.

This tool emerges when there is increased number of challenges in writing second language. Even native speakers said that writing second language is more uneasy than writing in their first language (Nunan, 2001). There are various implications for second language composing experts when all is said in done and for OWL originators all the more particularly. Concerning suggestions for second language composing experts, it is clear from the discoveries over that materials from North American-based OWLs will require unique thought before being sent in the second language composing classroom. This may incorporate the need to alter OWL assets to be all more semantically suitable. Notwithstanding, one ought to again take note of that numerous OWLs contain copyrighted material and adjustment may not be a choice. The Purdue OWL, for instance, enables clients to utilize and download its assets for instructive purposes, yet it does not allow any alteration of assets. These constrictions are spelled out in the Purdue OWL's Fair Use Policy (Purdue OWL, 2013b). Another real thought for experts might be the need to platform North American $O W L$ materials, especially looking at that as some of these assets might be socially bound, and that their importance may not be as solid for those not associated into Western artistic and scholastic customs.

\section{LITERATURE REVIEW}

For the past twenty years, people have heard many times about online learning. It might be tempting for enthusiasts to say that online learning will replace traditional classroom. One thing that should be underlined is that online learning will only complete variety of the learning process. An abundance of studies have examined online learning. Some of them explore the effectiveness through a number of criteria just like retention, achievement, and even satisfaction. Specifically for those who learn about second language writing, it is not just a piece of cake. Some experts say that writing is the most difficult to learn compared with listening, speaking, and reading. For writing, many teachers admit that learning it in the classroom will not be enough for students. Good writing takes more time for 
practices. Therefore, there is a need of an online support tool for helping the learners to practice write and write for unemptied time. In this case, integrating Information and Communication Technology (ICT) for learning is essential. Technology has a big role to help education between learners as well as teachers across curriculum and supply chances for communication (Dawes, 2001). Even in and outside the classroom, considering ICT is suitable for teaching and learning process (Laabidi, 2016).

This review tries to explain what is good and what should be improved in the study dealing with the tool which can support for learning writing. The analysis will be based on Guideline for review article by Philip Mayer (2009). For the first point still in the part of introduction, here the researcher will summarize the study. Not only summarizing, but also giving additional resource theories which support the statement of the researcher. The article that has been reviewed has tremendous relations with the use of technology for teaching and learning process. As we know that nowadays the process of learning rapidly goes following the development of Information and Communication Technology (ICT). The implementation of technologies especially for learning has become the main purpose of educational reforms (Chouit et al, 2017). As already been declared by Khaloufi \& Laabidi (2017), integrating ICT really assists the teacher in teaching processes. Unfortunately, in that study also found that the lack of teacher's skill in using the technology is still statistically significant. The teachers are needed to develop sufficient both knowledge and skill about technologies such as operating computers and using the internet. Thereunto, the growth of ICT in this modern era is uncontrollably fast. Even it unexpectedly influences modern society (Laabidi \& Laabidi, 2016). Therefore, the current study dealing with optimization the use of technology will take more interest to be conducted. The result of the study must has largely amount of effect that make the user get easier, in this case is learners as well as teachers.

The second point the researcher tries to share an explanation related to OWL's history and the process of it. More specific for Purdue OWL, this research actually is further research of Paiz own study (2014). In Purdue OWL, there are two coordinators operating the web, one for content and one for technical issues. Those two are doctoral students who have had some training and experience in teaching writing and in professional writing (Paiz, 2017). Next, I attempt to give analysis on methodology that the researcher uses to conduct his study. Furthermore, the analysis is continued to the developing writing skill by using OWL, because I myself feel doubt whether there is difference between this writing tool and another internetbased tool. The process of writing in this case is not as easy as writing first language. In line with Contrastive Analysis Hypothesis, the learners will easier to learn if the rule of first language is same as second language. And will be more difficult if the rule of first language is different from second language (Lightbown \& Spada, 2001 p.35). This also supported by Saville-Troike (2006 p.177), although languages are learnable, not all second languages are equally easy for learners of particular first languages to acquire. Ultimately, the last part of this review is going to talk about conclusions and future directions, the overall points of the tool to assist 
writing by exposing the "easy to write" atmosphere around the environment. The quality of the environment, especially language environment, is of paramount importance to success in learning new language in this case is second language (Dulay et al, 1982).

In his current research, Paiz investigates the uses of and attitudes towards OWLs as second language writing support tools. He attempts to delve more how the teachers feel when teaching writing using OWLs in their class. He also aspires to know the teachers' opinion towards Purdue OWL as one most valuable resource for EFL students. Therewith, by using interview and survey-internet based, he wants to find out whether or not general writing, ESL writing, and EFL writing should be separated every section on the Purdue OWL. Overall, Paiz (2017) emphasizes on the practitioners' implementation of the uniqueness of OWL. Moreover, the long goals of using OWL as supporting writing tool are promote and develop learners' autonomy in and outside of the classroom. The result of this finding, especially in interview result, is not really satisfying because the respondents who give responds are less than what the researcher expected. Only fifteen percent who give respond. As my own consideration, I think the researcher forget to do preliminary study first. He should conduct mini survey before doing the big one. Preliminary study is useful in order to prevent barriers when collecting the data needed. Then because of this is qualitative research which also unfortunately use small sample in interview, the generalizability of the findings cannot be sufficient.

\section{RESEARCH METHODS}

Specifically, Paiz's study here focuses on Purdue OWL, but he also investigates the use of general OWL. As my guess, he is going to compare both of them, Purdue and the general one. So then the readers will know which one is better. And the fact is in line with the guess, using interview and survey as instruments, the researcher find out that the Purdue OWL is being one of the most comprehensive and most utilized OWLs. I agree with this point because Purdue OWL offers facilities more than others. It provides reputable resources, writing assistance, and offering feedback (Bergmann et al, 2014). In line with the result on internet-based survey used by the researcher, one hundred thirty-five respondents from two hundred sixty give positive responses toward integrating Purdue OWL in their teaching and learning process. In this case, the researcher does the survey with considering the demographics of national contexts, ranging from the United States, Asia, Europe, until Africa.

One thing that should be the focus, the researcher here does not obtain an equal portion for each area. The majority responses come from the United States. In my opinion, it shows that the use of Online Writing Labs especially for writing second language does not evenly spread out. Even for general OWL, the finding based on the result shows that $52.38 \%$ of the respondents use it only sometimes (Paiz, 2017). Another interesting to consider in my mind is the questions which are designed for the survey. There are four questions, and three of them explore about general OWL penetration and usage, only one which refers to specific Purdue OWL. Contrary to the fact that the researcher explains in the first introduction, he said that 
he tries to focus on Purdue OWL, but then the questions mostly refers to general OWL. The proportion of the questions should not be like that. The researcher has to be consistent with what he is going to find and in what way to find that. Therefore, the questions for finding the Purdue OWL usage information should much more than the general one:

1. Do you use Online Writing Labs (OWLs) to assist in the teaching of writing? $\rightarrow$ General OWL

2. Do you use Purdue OWL to assist in the teaching of writing? $\rightarrow$ Purdue OWL

3. How often do you use Purdue OWLs to assist in the teaching of writing? $\rightarrow$ Purdue OWL

4. Which of the following best describe how you use Purdue OWLs to assist in the teaching writing? $\rightarrow$ Purdue OWL

5. Did you know that the Purdue OWL has ESL specific resources? $\rightarrow$ Purdue OWL

Based on the question arisen, the researcher will obtain more information about the respondents' attitude and use towards the Purdue OWL. Thereunto, there is a positive side in his survey. At the end of the questions, the researcher also makes a list for what EFL practitioners need in order to enrich the way of teaching writing. And the result shows a high level of possible interest, there appears to be less enthusiasm for more dynamic resources (audio and/or audio/visual lectures).

Besides using internet-based survey, the researcher also uses interviews. The interviews are open-ended and conducted via email right after the survey data collection window closed (Paiz, 2017). In this process, the researcher uses seven interviews to 46 respondents. Unfortunately, only $15 \%$ give responses. Once the interview collection closed, the researcher compiles all answer to individual questions, so that themes can be identified across individual answer to particular question. From the result of interviews also, the researcher get conclusion that most of the interviewees prefer to use website than a book. In line with this finding, I personally agree that technology influence many aspects in the development of knowledge and the way to learn the knowledge itself. Undoubtedly, learners' motivation will grow up if the learning is integrated with technology than traditional one. Motivation involves the attitudes and affective states which influence learners to learn second language (Ellis, 1997). Especially in the classroom, writing lessons which always consist of the same routines, patterns, and formats have been shown to lead to a decrease in attention and an increase in boredom, and then also decrease the motivation of learning (Lightbown \& Spada, 2001, p.57).

\section{FINDINGS \& DISCUSSION}

The researcher analyzes some cases that should be developed in the article by M. Paiz related to the use of Purdue Online writing labs. By utilizing online interviews and survey directly to particular users of and the website of Purdue Online writing labs, the findings come up including five dimensions. First, Purdue Online writing labs can only be accessed by professional and students studied in 
Purdue University and those who have good understanding about that website. It means that the teachers who want to optimize that kind of online labs for the process of teaching and learning writing should have adequate capabilities. In many cases, this kind of effort can be developed further by providing a kind of teachers' training just like in any professional development program. If the teachers have good attitudes focusing on the application of this technology, they are able to get the benefit of adopting it into the teaching and learning process without difficulty (Laabidi, 2016). Moreover, Harries (2002) says that confident teachers, who are able to operate the technology and have a great creativity for exploring it, will result in the increase of students' motivation. Hence, many studies have proved that the use of ICT for education can motivate students to learn (Kelleherr, 2000; Skinner, 2003; Grabe, 2007).

Second, as a good point, this kind of online writing labs includes parent as one of the suggested resources. In this case, the parents are having a guideline to instruct or give writing exercises suitable for their children. Moreover, this part of resources also provide many more points of examples for developing outline, paragraphing, quoting, summarizing, even for avoiding plagiarism. Additionally, there is found that the parents' contribution is significantly important to trigger their children motivation.

Third, this kind of online learning platform serves many exercises related to sharpen writing ability. There are some exercises focusing on grammar, punctuation, spelling, structure, and sentence style. A good thing from sentence style exercise, there is a direction how to eliminate wordiness. Unfortunately, the component of exercises still has to be completed. There is no chapter discussing about the content of the writing itself. It seems like you will be free to write with concerning more on mechanism yet without converging on the content.

Fourth, focusing on the need of conducting writing product of many researchers, this online writing labs can be adopted as the media for producing any kind of writing. The content of this point should provide visitors and scholars with more information about work in theory and research that contributes literacy resources accessed by millions of global users every years. This research area will turn to be useful for both who wants to do the research and those who provide a bunch of information for being research.

Last, but not least, Online Writing Labs which has already been exist still needs appropriate strategies to be used effectively. As we know that many similar learning platform provide writing checker but the users have no information about what will be done for next. Again, learning writing is not only checking the mechanical components but more also important is appearing and arranging the idea to be writing products which assist the reader being rich of information given.

According to Center for Teaching Quality, effective writing uses specific methods to capture the audience's attention, validate readers' concerns, acknowledge their values, and connect with their emotions. The following strategies can be used to create effective written communication:

1. Introducing or supporting ideas through powerful storytelling and compelling anecdotes. 
2. Promoting the credibility of the author and his/her sources.

3. Framing the message through the lens of the audience's values, needs, and emotional sensibilities.

4. Connecting to the audience through specific word choice that acknowledges readers' values, needs, and priorities.

5. Avoiding insider jargon, such as highly technical terms or education-specific acronyms that will disconnect the audience from the topic or ideas.

6. Using inductive and deductive reasoning to craft powerful arguments.

7. Incorporating visual components (graphs, tables, images, or charts) to reinforce ideas, arguments, and calls to action.

In the era of rapid technology, almost all of the teaching and learning process are forced to utilize and integrate technology while delivering the knowledge. Specifically internet as one of the learning tools, it has expanded rapidly in the world during the last decade (Stepp, 2002). According to other studies, the integration of the internet in writing was an effective and powerful media to improve ESL students' writing skills (Al-Jarf, 2004). The use of technology can build students' motivation to write more and more (Yunus et al, 2010). In addition, as technology becomes more prominent, it would be a "waste" not to exploit its potential in teaching and learning esecially for secong language. Besides, today's children are "more interested in learning by using a computer compared to more old-fashioned methods" (Graddol, 1997). The branch sources of internet for learning are invinite. One of them is the use of website or labs. The Writing Lab uses computers as an integral part of the tutoring and learning process, and tutors use them in a growing number of ways: to improve students' computer writing processes, to help students effectively access OWL resources, and to demonstrate how to access and evaluate sources on the Internet (Purdue OWL web). OWL as Online Writing Labs, in this review, is believed by the researcher can support the writing activity. Unfortunately, Paiz (2017) in his study does not show how important developing writing skill and how the way of using OWL in teaching and learning process. Moreover, he establishes that many of the teachers, practitioners, and even second language writers are success in implementing OWL as their tool to strengthen their writing ability.

\section{CONCLUSION}

Promoting an interactive tool for make learners easier to write is one of the valuable ways to enhance their motivation and ability especially for learning a second language. Purdue OWL assists to get that goal. This learning platform provides many sub tools which have their own function in order to help visitors and users practice writing. In Paiz's (2017) article, he explained the utilization of Purdue Online Writing Labs only in urban area which has no obstacle with the accessibility of technology. That is the reason why there is a need of consideration in developing local/regional OWLs which can address the needs by being designed from the ground up to meet the linguistic needs of local users. Developing this kind of support tools requires encouragement both from teachers and researchers as sources. 
Furthermore, learners also should be motivated to learn outside the school by their parent. In this case, the parents take big control in order to assist their children becoming enthusiastic learners. By making use of Information and Communication Technology (ICT), learners are able to have more chances to pick the knowledge up wherever and whenever. Hence, if learners interested in the media for learning, they will take into account every information obtained. For teachers, integrating ICT in their teaching and learning process is adequate essential. Therefore, in this case, the teachers should know how to operate the online learning platform with a good understanding.

As suggestions, when conducting that kind of learning tool, be focus on what the learners needs. The future researchers will know the learners needs if they do preliminary study and spread out the instrument of collecting data by inviting nonsmall number of respondents so that the result of finding can be generalizable to other populations of practitioners. Online Writing Labs especially Purdue OWL offers many facilities such as sources and feedback. It will be more sophisticated if all the facilities in online writing labs can be compressed to mobile application so as learners can be more engage to the learning only by open up their mobile phone. Those can be developed more and be used by practitioners so that learning a second language especially for writing will be more fun and interesting. And if the existed tool has been applied, it is a must for monitoring and evaluating the process to be better development.

\section{REFERENCES}

Al-Jarf, R.S. (2004). Effects of Online Learning on Struggling ESL College Writers. Riyadh: King Saud University.

Bergmann, L., Conard-Salvo, T., \& McCall, M. (2014). Annual Report: Writing Lab at Purdue University-May 20, 2013 to May 9, 2014. https://owl.english.purdue.edu/printables/2014_Wlab_report.pdf.

Brown, H. D., Lee, K. (2015). Teaching by Principles. An Interactive Approach to Language Pedagogy. Fourth Edition. New York: Pearson Education, Inc.

Chouit, D., Nfissi, A., Laabidi, H. (2017). Exploring the Correlation between Professors' Use of ICT in Teaching and the Levels of Institutional Support. JELTL (Journal of English Language Teaching and Linguistics), 2 (1). doi: http://dx.doi.org/10.21462/jeltl.v2i1.39

Dulay, H., Burt, M., Krashen, S. (1982). Language Two. New York: Oxford University Press.

Dawes, L. (2001). What stops teachers using New Technology. In M. Leask (Ed.), Issues in Teaching using ICT (pp61-79). London: Routledge.

Ellis, R. (1997). Second Language Acquisition. New York: Oxford University Press.

Grabe, M., \& Grabe, C. (2007). Integrating technology for meaningful learning $\left(5^{\text {th }}\right.$ ed). Boston, MA: Houghton Mifflin.

Graddol, D. (1997). The future of English: A guide to forecasting the popularity of the English language in the 21st century. London: Glenton Press. 
Kelleher, P. (2000). A review of recent developments in the use of information communication technologies (ICT) in science classrooms. Australian Science Journal, 46 (1), 33-38.

Khaloufi, A., Laabidi, H. (2017). An Examination of the Impact of Computer Skills on the Effective Use of ICT in the classroom. Indonesian Journal of EFL and Linguistics, 2 (1).

Laabidi, H. (2016). Barriers Affecting Successful Integration of ICT in Moroccan Universities. JELTL (Journal of English Language Teaching and Linguistics), $1(3)$.

Laabidi, Youssouf. (2016). A Quantitative Examination of Factors that influence Technology Integraion in Higher Education System. Indonesian Journal of EFL and Linguistics, 1(2).

Lightbown, P. M., Spada N. (2001). How Languages Are Learned. Second Edition. New York: Oxford University Press.

Nunan, D. (2001). Second Language Learning and Teaching. Boston: Thompson Publishing Company.

Paiz, J. M. (Ed.). (2014). Alumni Annotations: The Purdue OWL $20^{\text {th }}$ Anniversary

Paiz, J. M. (2017). The Asian EFL Journal Quarterly March 2017. Uses of and Attitudes towards OWLs as L2 Writing Support Tools. Vol.19, Issue 1.

Saville M.-Troike. (2006). Introducing Second Language Acquisition. Cambridge: Cambridge University Press.

Skinner, N. C., \& Preece, P. F. W. (2003). The use of information and communication technology to support the teaching of science in primary schools. International Journal of Science Education, 25(2), 205-219.

Stepp-Greany, J. (2002). Student Perceptions on Language Learning in a Technological Environment: Implications for the New Millenium. Florida: Florida State University.

Yunus, M.M., Chua, P.L., Maimun, A.L. \& Rizauddin, R. (2010). Evaluation of ICT usage for general or English learning purposes. WSEAS Transactions on Information Science and Applications, pp. 205-211. 